\title{
Molecular Catalysis for Precise Olefin Polymerization and ROP 2015
}

\author{
Carl Redshaw \\ Fax: +44-1482-466410 \\ Academic Editor: Keith Hohn \\ Received: 24 March 2016; Accepted: 30 March 2016; Published: 31 March 2016
}

Department of Chemistry, University of Hull, Hull HU6 7RX, UK; c.redshaw@hull.ac.uk; Tel.: +44-1482-465219;

\section{Background}

The growth of emerging markets, particularly in the Far East, has fuelled the demand for new plastic materials. This in turn has stimulated both academic and industrial interest in the design of catalyst systems for which new Intellectual Property (IP) can be generated, and in new polymeric materials possessing desirable properties such as biodegradability.

Underpinning much of the work is synthetic chemistry and, in particular, ligand-set design. The ability to tune the electronic and steric properties of the resultant metal catalysts and thereby influence both the catalytic activity, as well as the resultant polymer properties, is proving particularly fruitful. Traditionally, early transition metals have been employed particularly for polyolefin synthesis, but in recent years late transition metals have emerged as intriguing alternatives, and each are attracting industrial interest [1]. For ring opening polymerization systems, catalysts incorporating elements from many parts of the periodic table are showing promise [2].

In this Special Issue, manuscripts focusing on aspects of new catalyst systems for the homo- or co-polymerization of $\alpha$-olefins, on the ring opening polymerization (ROP) of $\varepsilon$-caprolactone, and on co-polymerizations involving $\mathrm{CO}_{2}$ /cyclohexene oxide are presented [3-8]. This work will be of immense interest to those involved in catalyst design, organometallic chemistry and polymer synthesis.

\section{The Present Issue}

I would like to thank all of the authors and reviewers for contributing to this special issue, which together makes an excellent collection of works. Furthermore, I would like to thank Mary Fan and her editorial team for their sterling efforts in putting this issue together and the Editor-in-Chief Keith Hohn.

This issue comprises six research papers (articles).

- In the first contribution, Solan and coworkers have employed bulky 2-imino-6-(1-napthyl)pyridine ligation at aluminium, and have studied the impact of employing $\mathrm{N}$ bound aryl groups bearing para substituents with differing electronic properties on the ROP of $\varepsilon$-caprolactone. Upon activation with benzyl alcohol, the system employing the electron donating iPr group at the para position proved to be the most active, for example at $100 \%$ conversion was achieved at $50{ }^{\circ} \mathrm{C}$ over $1 \mathrm{~h}$. However, given the bromide derivative was move active that that containing a para-hydrogen, the rate of polymerization is thought to be determined by a number of factors including alkoxide nucleophilicity and the Lewis acidity at the metal [3]. The related 2-(Phenyl-2-olate)-6-(1-amidoalkyl)pyridine dimethylaluminium complexes have also shown promise in the ROP of $\varepsilon$-caprolactone [9].

- In the second paper, Huang and coworkers studied the use of group IV (Ti, $\mathrm{Zr}$ ) complexes incorporating $N, P$-chelate ligation of the diisopropylphosphorus-phenylamine type. Upon activation with MAO, high activity was observed for both the polymerization of ethylene and the copolymerization of ethylene/ $\mathrm{N}$-acetyl-O-(dec-9-enyl)-L-tyrosine with high co-monomer 
incorporation $(2.56 \mathrm{~mol} \%)$ for the latter case. The molecular weights associated with the copolymers were somewhat lower than those of the homopolymers [4].

- In the third paper, our laboratory continued our investigations into the coordination chemistry (and resultant catalytic properties) of bulky bi-phenols of the type 2,2'- $\mathrm{RCH}\left[4,6-(\mathrm{tBu})_{2} \mathrm{C}_{6} \mathrm{H}_{4} \mathrm{OH}\right]_{2}$ $(\mathrm{R}=\mathrm{Me}, \mathrm{Ph})$, tri-phenols 2,6-bis(3,5-di-tert-butyl-2-hydroxybenzyl)-4-methylphenol and tetra-phenols $\alpha, \alpha, \alpha /, \alpha /$-tetrakis(3,5-di-tert-butyl-2-hydroxyphenyl)-p- or -m-xylene [10,11]. In this contribution, we focus on bis(imido) molybdenum(VI) complexes and report on their ability to ring open polymerize $\varepsilon$-caprolactone. Reasonable activity was only achievable at temperatures of $100{ }^{\circ} \mathrm{C}$ or more over time periods of at least $1 \mathrm{~h} \mathrm{[5]}$.

- In the fourth article, Michiue, Mitani and Fujita of the Mitsui Chemical Corporation studied substituent effects when using activated rac-[Me $\left.2 \mathrm{Si}(\text { Indenyl' })_{2}\right] \mathrm{ZrCl}_{2}$ (where Indenyl' is a generic indenyl grouping) on products containing pendant vinyls and vinylenes, which result from copolymerizations involving ethylene/1,3-butadiene or propylene/1,3-butadiene. Systems were identified which afforded copolymers with predominantly vinyl groups [6]. This work built on preliminary screening results for which it was found that catalysts inserting $\alpha$-olefins via 1,2-insertion tend, particularly in the presence of steric regulation, to produce olefin/butadiene copolymers having pendant vinyl groups [12].

- The final two papers of this Special Issue are from the group of Darkwa. With Nazaki and coworkers, they have investigated the ability of bis(pyrazole)zinc(II) benzoates to act as catalysts for the copolymerization of $\mathrm{CO}_{2}$ with cyclohexene oxide. Such systems were found to be active without the need for a co-catalysts and could operate at low $\mathrm{CO}_{2}$ pressures $(1.0 \mathrm{MPa})$. Copolymers with high carbonate content $(\leqslant 98 \%)$, low to moderate molecular weight $(<12300 \mathrm{~g} / \mathrm{mol})$ and with glass transition temperatures suggestive of alternating copolymers were isolated. Highest observed catalytic activity was achieved when employing catalysts with high electrophilicity at the metal, specifically derivatives bearing 3,5-dinitrobenzoates and 2-chlorobenzoates [7]. The second Darkwa contribution describes a number of iron(III) complexes for 1-hexene polymerization and extends their work on tridentate $O, N, N$-phenoxysalicylaldimine containing complexes [13]. Upon activation with $\mathrm{EtAlCl}_{2}$, these systems afforded low molecular weight poly(1-hexene) with branched microstructures; the presence of dominant longer branches were indicative of 2,1-insertion of the monomer. Single-site behaviour was observed for these catalysts over a variety of catalytic conditions [8].

\section{References}

1. Baier, M.C.; Zuideveld, M.A.; Mecking, S. Post-Metallocenes in the Industrial Production of Polyolefins. Angew. Chem. Int. Ed. 2014, 53, 9722-9744. [CrossRef] [PubMed]

2. Arbaoui, A.; Redshaw, C. Metal catalysts for $\xi$-caprolactone polymerisation. Polym. Chem. 2010, 1, 801-826. [CrossRef]

3. Armitage, A.P.; Boyron, O.; Champouret, Y.D.M.; Patel, M.; Singh, K.; Solan, G.A. Dimethylaluminium complexes bearing napthyl-substituted pyridine-alkylamides as Pro-initiators for the efficient ROP of $\xi$-caprolactone. Catalysts 2015, 5, 1425-1444. [CrossRef]

4. Wang, J.; Shi, X.; Chen, Y.; Li, H.; Zhang, R.; Yi, J.; Wang, J.; Huang, Q.; Yang, W. Copolymerization of Ethylene and Vinyl Amino Acidic Ester Catalyzed by Titanium and Zirconium Complexes. Catalysts 2015, 5, 1831-1845. [CrossRef]

5. Al-Khafaji, Y.; Prior, T.J.; Elsegood, M.R. J.; Redshaw, C. Molybdenum(VI) Imido Complexes Derived from Chelating Phenols: Synthesis, Characterization and $\varepsilon$-caprolactone ROP capability. Catalysts 2015, 5, 1928-1947. [CrossRef]

6. Michiue, K.; Miani, M.; Fujita, T. Synthesis of Ethylene or Propylene/1,3-Butadiene Copolymers Possessing Pendant Vinyl Groups with Virtually No Internal Olefins. Catalysts 2015, 5, 2001-2017. [CrossRef] 
7. Lephoto, M.; Nakano, M.L.; Appavoo, D.; Owaga, B.O.; Nozaki, K.; Darkwa, J. Pyrazole Supported Zinc(II) Benzoates as Catalysts for the Ring Opening Copolymerization of Cyclohexene oxide and Carbon Dioxide. Catalysts 2016, 6. [CrossRef]

8. Yankey, M.; Obuah, C.; Darkwa, J. Homo-Polymerization of 1-Hexene catalyzed by $\mathrm{O}^{\wedge} \mathrm{N}^{\wedge} \mathrm{N}$ (Salicylaldimine)Iron(III) Pre-Catalysts to Branched Poly(1-hexene). Catalysts 2016, 6. [CrossRef]

9. Alkarekshi, W.; Armitage, W.; Boyron, O.; Davies, C.J.; Govere, M.; Gregory, A.; Singh, K.; Solan, G.A. Phenolate Substituent Effects on Ring-Opening Polymerization of $\varepsilon$-caprolactone by Aluminum complexes bearing 2-(Phenyl-2-olate)-6-(1-amidoalkyl)pyridine Pincers. Organometallics 2013, 32, 249-259. [CrossRef]

10. Ge, F.; Dan, Y.; Al-Khafaji, Y.; Prior, T.J.; Liang, L.; Elsegood, M.R.J.; Redshaw, C. Vanadyl phenolate complexes for ring opening homo- and co-polymerisation of $\mathcal{E}$-caprolactone, L-lactide and rac-lactide. RSC Adv. 2016, 6, 4792-4802. [CrossRef]

11. Redshaw, C.; Walton, M.J.; Elsegood, M.R. J.; Prior, T.J.; Michiue, K. Vanadium(V) tetra-phenolate complexes: Synthesis, structural studies and ethylene homo-(co-)polymerization capability. RSC Adv. 2015, 5, 89783-89796. [CrossRef]

12. Michiue, K.; Ishii, S.; Miani, M.; Fujita, T. Copolymer of Olefin and Conjugated Diene and Process for Producing Same. Patent WO2010113975, 7 October 2010.

13. Yankey, M.; Obuah, C.; Guzei, I.A.; Osei-Twum, E.; Hearne, G.; Darkwa, J. (Phenoxyimidazolylsalicylaldimine)iron Complexes: Synthesis, Properties and Iron Catalysed Ethylene Reactions. Dalton Trans. 2014, 43, 13913-13923. [CrossRef] [PubMed]

(C) 2016 by the author; licensee MDPI, Basel, Switzerland. This article is an open access article distributed under the terms and conditions of the Creative Commons by Attribution (CC-BY) license (http://creativecommons.org/licenses/by/4.0/). 